$$
\begin{aligned}
& \text { CONF-750962--1 } \\
& \text { CONF-750954--1 }
\end{aligned}
$$

RADIATION DAMAGE CONSIDERATIONS

By

\title{
B.R.T. Frost
}

Presentation at the Battelle Colloquium

Fundamental Aspects of Structural Alloy Design

Battelle Memorial Institute

Seattle, Washington and Harrison Hot Springs, B.C., Canada

September 15-19, 1975

AND PUBLICATION IN PROCEEDINGS

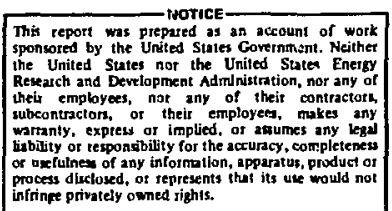

MASER

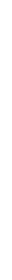




\section{RADIATION DAMAGE CONSIDERATIONS*}

by

B.R.T. Frost

ARGONNE NATIONAL LABORA'TORY

Argonne, Illinois 60439

August 1975

rw

Distribution:

1-3. E.N. Pettitt

4. M.F. Adams

5. R.W. Weeks

6. B.R.T. Frost

To be presented at the Battelle Colloquium, Fundomental Aspects of Structural AZZoy Design, Seattle, Washington and Harrison Hot Springs, B.C., Canada, September 15-19, 1975

*Work supported by the U.S. Energy Research and Development Administration. 


\section{RADIATION DAMAGE CONSIDERATIONS*}

by

B. R. T. Frost

Materials Science Division

Argonne National Laboratory

Argonne, Illinois 60439

August 1975

To be presented at the Battelle Colloquium, Fundamental Aspects of Structural AlZoy Design, Seattle, Washington and Harrison Hot Springs, B.C., Canada, September 15-19, 1975

*Work supported by the U.S. Energy Research and Development Administration. 


\section{RADIATION DAMAGE CONSIDERATIONS * \\ by}

B. R. T. Frost

Materials Science Division Argonne National Laboratory Argonne, Illinois 60439

\section{ABSTRACT}

The designs of nuclear fission and fusion power plants do not, in general, appear to make unusual demands on materials in terms of mechanical-property requirements. Superficlally, the needs of the designer can be met by commerclally available alloys. However, the radiation environment produces unique effects on the composition, microstructure, and defect population of these alloys, resulting in time-dependent and time-independent changes in mechanical properties. These changes must be quantified for the designer.

To illustrate these problems, the matertals needs of the core of a Ly quid-Metal Fast-Breeder Reactor (LMFBR) and of the first wall of a fusion reactor are discussed. In the case of the LMFBR core, the phenomenon of vold swelling causes serious design problems, and a search is being made for a low-swelling alloy that has adequate mechanical properties. The fusion reactor poses different problems because the neutron energy is high (14 MeV) and is accompanied by a high flux of charged particles. The long-term choices for a wall material have been narrowed to vanadium and niobium alloys.

* Work supported by the U.S. Energy Research and Development Administration. 
In the search for low-swelling alloys, it has become clear that minor elements play an important role in determining the nature of the radiation effects. The segregation of minor elements to vold surfaces and the dispersion and reformation of second-phase precipitates are two Important radiation-induced phenomena that require additional study in view of their influence on void swelling and high-temperature properties.

\section{INTRODUCTION}

The mechanical properties required of alloys for use in nuclear plant:s are basically similar to those required in any power plant. In water-moderated fission reactors operating at temperatures below $800^{\circ} \mathrm{F}$ $\left(430^{\circ} \mathrm{C}\right)$, the materials generally deform elastically, and design emphasis is placed on mechanisms of crack initiation and propagation. In gascooled and sodium-cooled fission reactors and in fusion reactors, materials are generally operating above $400^{\circ} \mathrm{C}$. In this case, the design emphasis is on high creep strength and ductility and on creep-fatigue Interactions (cumulative damage), 1.e., on time-dependent properties. Bowever, the temperatures and stresses involved are within the ranges encountered in modern steam and gas turbine systems.

To meet these requirements and to have the capability of withstandIng the generally corrosive environments of these reactors, conventional austenitic and ferritic steels have bean used, together with zirconium alloys that were specially developed for use in water reactors. Fo: the future, Increasing emphasis will be given to pyecipitation-hardened 
alloys and to the bcc metals and alloys. This will permit increased operating temperatures and thermal efficiencies. .

The unique feature of fission and fusion reactors is the radiation environment. Energetic neutrons, gamma rays, and charged particles produce radiation damage and localized heating within the bulk of the alloys. Radiation damage, for the purposes of this discussion, involves the production of lattice defects and transmutation products. The production of defects may lead to enhanced diffusion (including enhanced creep), defect cluster formation, and void formation. The dispersion of precipitates into the lattice under energetic particle bombardment is a special case; a dynamic, flux-dependent equilibrium is established between dispersion and reprecipitation, which is enhanced by radiation. Transmutations can produce hydrogen and hellum gases and other metallic species, e.g., nlobium becomes transmuted to zirconfum, so that the pure niobium wall of a fusion power reactor would become a $\mathrm{Nb}-10 \% \mathrm{Zr}$ alloy after $\sim 20$ years. Thus, although conventional alloys have of ten been selected for nuclear applications, their long-term behavior in service is quite different from that in a nonnuciear plant.

A basic, and as yet only partially solved, problem is to understand the special effects of the radiation environment on alloy structures and properties. The problem is complex because two types of processes occur simultaneously: (1) flux-dependent processes, which include diffusion (atomic transport), diffusion creep, and stress-relayation, and (2) doseor fluence-dependent processes, which produce changes in chemical composition and microstructure. These two types of processes are intersctive, i.e., the radiation-enhanced creep rate will change with time, 
even when all other factors are held constent, because the microstructure changes. Hence, it is difficult to select or design alloys for nuclear applications because we do not adey lately understand these time-dependent and time-independent processes and their interrelationships. In the current research approach, an attempt is made to isolate the important radiation-induced phenomena and to test the effects of different initial microstructures and compositions on these in a systematic manner.

In an effort to give more physical meaning to the present discussion, two examples of the importance of considering radiation effects in the selection of alloys will be cited from nuclear systems current1y under developient. The first is the Liquid-Metal Fast-Breeder Reactor (LMFBR). The core of this reactor is a compact heat source, which is assembled from a number of closely packed hexagonal subassemblies, as 1llustrated In Fig. 1, each of which contains hundreds of small diameter, metal-clad fuel elements (Fig. 2). The temperature range to which the fuel assemblies and rods are exposed is $\sim 400-650^{\circ} \mathrm{C}$. The ueutron flux is energetic and of high intensity; typically in the range of from $10^{15}$ to $10^{16} \mathrm{n} / \mathrm{cm}^{2} / \mathrm{sec}$. The fuel-element tubes are required to resist the internal pressure that arises from fuel swelling and fission-gas release. A universal cholce for these tubes has been 207 cold-worked Type 316 stainless steel, because of 1ts good creep strength, reasonable ductility, ease of fabrication and manipulation, and resistance to hot sodium. During its lifetime exposure to the neutron flux, the stainless steel swe1ls, because of the formation of volds, in the manner shown graphically in Fig. 3. It also loses 
nonuniform ductility as a result of combination of interior hardening of the grains and grain-boundary weakening. The neutron flux is nonuniform across the reactor core; hence, nonunifora swelling of fuel assenblies will occur, leading to distortion. (1) Figure 4 shows the manner in which tho subassemblies are held in the core, whereas Fig. 5 shows the direction of distortion due to swelling. The distortion could make the utinading of the core impossible. This problea cannot be solved by spacing the hexagonal cans further apart, since that will lead to an unacceptably high 1088 of neutrons that are needed to breed new fuel. Some relief is afforded by radiation-injuced stress relaxation or creep; the magnitude of radiation-induced creep is 1llustrated by results of a uniaxial creep test conducted on Type 316 stainless steel in the core of the EBR-II fast reactor, shown in Fig. 6. The creep may be sufficient to relax the interference stresses caused by bowing, but it is difficult to strike the correct balance between the two processes. Hence, a search is belng made for a swelling-resistant alloy that also has adequate strength and residual ductility.

Vold swelling, the microstructural form of which is 11lustrated In Fig. 7, is caused by the biased flow of interstitials to dislocations and other sinks, leaving a net excess of vacancles that cluster in assoclation with heliua produced by $(n, a)$ transmutations $i n$, for example, iron, chromium, and nickel. $(2,3)$ An increase in the number of sinks for the vacancles should reduce swelling; this has been sought through the use of two-phase alloys such as $\gamma^{\prime}$ In a nickel matrix (e.g., PE16), by a change in stacking-fault energy, and by changes in minor alloying elements that alter the vold-nucleation process. 
Th1s 18 essentially a "blological" approach in which any alloys are belng tested. Hence a rapid screening method. Is required. In current fast reactors, several years are required to attain an adequate neutron dose, which is unacceptable. To overcone this problem, energetic charged particles (typically $4 \mathrm{KeV}$ ) are used to produce intense but localized danage in alloy samples; vold forantion is analyzed by trantission-electron wicroscopy, which also pernits interrogation of other afcrostructural changes. This screening process has ylelded valuable indications of the compositional factors that produce alloys with $10 w$ swelling rates. Figures $8 \mathrm{a}$ and $8 \mathrm{~b}$ show the results of tests on a range of comercial and synthetic Fe-Cr-il alloys, sone of which contain other elenents such as Al and Mo. It should be noted that the swelling rate becones low at nickel contents in excess of 40 wt $z$. In Fig. 9, the swelling rate of an Fe-15Cr-20N1 alloy 18 plotted as a function of minor alloy additions. The effectiveness of TI and SI additions is significant; a combination of these two elements at approxiately the 1 wt 7 level of each has been shown to reduce drastically the swelling of Type 316 stainless steel. These results show that several low-owelling alloys are avallable which fall within the allowed composition 1infts for existing comercial alloys. Th1s is important because of the long tine required for code acceptance of new alloys.

To date, fusion reactors have not demonstrated scientific feasibilIty, and they probably will not be in comercial service before the year 2000 A.D. However, because of the optinism generated by recent plasma physics experiments, considerable thought has been given to the probable materfals requirements of such reactors and to the peculiar environment 
to which the materials will be subjerted. The nost popular reactor concept at this time is the Tokamak, shown schematically In Figs. 10 and 11. The most probable reaction for early fuston reactors is

$$
\mathrm{D}+\mathrm{T} \rightarrow{ }^{4} \mathrm{He}+\mathrm{n}+17.6 \mathrm{MeV} \text {. }
$$

Deuterium and tritfum are Ionized in the vacuum chamber of the Tokanak, compressed magnetically, and heated ohmically to an energy in excess of u10 keV. The break-even point (or sclentific feasibility) will be denonetrated when $n \tau ; 10^{14}$, where $n$ is the number of $10 n s / \mathrm{cm}^{3}$, and $\tau$ is the confinesent time in seconds. As shown in Fig. 12, the first wall will be subjected to bombardment by 14-MeV neutrons, charged and neutron particles, and short-wavelength radiation (Brensstrahlung). The neutrons will cause damage, Including surface sputtering, displacements, voids, gas bubbles, and me:-d]. atom transmutations. (4) They will pass into the 11thium blanket where most will be captured to produce tritium, but sone w111 be slowed down and w11 diffuse back Into the metal wall and cause some damage and transmutations. The charged and neutral particles and energetic neutrons will cause sputtering from the inner wall. (5) since plasma energy losses vary with $2^{4}$, where $Z$ is the atomic number of the sputtered wall atom, the wall must be made of (or coated with) a low $\mathrm{Z}$ uterial.

The radiation-damage processes in the fusion reactor first wall will Include vold swelling, radiation creep, and helium-induced loss of ductility. Thus, the selection of a suitable alloy for this application has sowe of the same elements of cholce as the LMFBR fuel tube. However, other factors are different, e.8., the displacement damage produced by 14-MeV neutrons versus fission neutrons, the transmutation rates, and the 
surface effects. The magnitude of these differences is indicated in tabulax form in Fig. 13, where the damage and transmutation rates in the rilobium wall of a fusion reactor are compared with these rates for stalnless steel in a fast fission reactor. Although the damage or displacement rates differ by only a factor of two, the transautation rates differ by much greater factors. The latter will cause large changes in mechanical and physical properties.

From a design viewpolnt, the fuston reactor flrst wall will be subjected to high thermal stresses but not high loading stresses. Design tolerances can be falrly loose, but differential swelling and excessive radiation-creep rates are to be avolded. The outer surface of the wall may be In contact with liquid Ifthium, which is used to generate tritium fuel.

In early experimental fusion reactors, wall temperatures may be as low as $400^{\circ} \mathrm{C}$, so that ferritic or austentic steels could be used (although data on 14-MeV neutron effects in these matertals w11l be needed). More efficient reactors will have higher wall tempezatures, possibly as high as $1000^{\circ} \mathrm{C}$ and certainly in excess of $600^{\circ} \mathrm{C}$. Since lithium is known to corrode nickel-base alloys and even stainless steels at these temperatures, the only materlals with an adequate combination of properties are the refractory metals nlobium, molybdenum, vanadlum, and their alioys. Nuclear considerations, such as the level of Induced radioactivity (which is important frcm the standpoint of maintenance and ultimate disposal), favor vanadium and 1 ts alloys as a long-term choice for first-wall material, with nioblum as a second choice. Fission reactor and Ion bombardment irradiations have been conducted on vanadium, ${ }^{(6)}$ niobium, ${ }^{(7)}$ and 
their alloys. The pure netals have high gwelling rates, but small alloyIng additions (e.8, $17 \mathrm{TI}$ or $\mathrm{Zr}$ ) raduce these considerably. No weaaurements of irradiation creep have been wade, although it has been shown that realistic levels of helium reduce the ductility markedly at temperatures above $700^{\circ} \mathrm{C}\left(\mathrm{Fig}_{\mathrm{g}}, 14\right)$.

These two examples of design problews 11lustrate the ways in which the radiation environment increases the difficulty of the task of alloy election for nuclear reactors. In the course of the work outlined above, additional complicating factors have become apparent. One has been wentioned, 1.e., the developwent of a different size and spacing of precipitates $^{(8)}$ in two-phase alloys, which will obviously influence the high-temperature mechanical properties. This is evident from the microstructural changes shown in a Mi-Al alloy during Irradiation (F1g. 15). Closely related to this effect is the promotion of diffusion-controlled phase transformations by irradiation. An alloy that normally is thermally stable may become unstable in a fast-neutron flux.

Minor alloying elements (or Impurities) have been shown to exert a major influence on radiation processes. First, it has been shown that tine size and number density of dislocation loops in the bcc metals is strongly Influenced by the level of the interstitial elements in solution. (9) Second, the void-swelling behavior of nioblum and vanadium is strongly influenced by the oxygen content of the metal. (10) For example, niobium forms an ordered void lattice at $7780^{\circ} \mathrm{C}$ when it contains oxygen in excess of w250 ppm, but it does not form an ordered lattice at $10 \mathrm{ppm}$; larger, randomly arranged voids are formed that produce a considerably higher swelling rate (Fig, 16). It is speculated that a very fine ordered 
precipitate of $\mathrm{NbO}$ may be formed at the higher oxygen levels, which provides nucleation sites for volds. As shown in Fig. 16, an ordered lattice of voids is not observed at $828^{\circ} \mathrm{C}$ but the influence of oxygen content on void size is evident.

Careful transmission-electron microscopy has shown that solutes with negative size factors segregate toward void surfaces. (11) A perticular case is an Fe-18Cr-8Ni-1Si alloy in which the silicon clearly segregated at the vold surfaces during electron irradiation (Figs. 17a and 17b). It has been shown theoretically that this can lead to a reduction in vold growth, ${ }^{(12)}$ and a kinetic model of the segregation process has been developed. (13) Possibly related to this effect is the empirical finding (mentioned earlier) that the addition of w1 wt $\mathrm{F}$ TI and 1 wt \% S1 to Type 310 stainless steel markedly reduces the swelling rate. (14)

A general conclusion from the findings on minor element effects is that the specifications uormally used for alloys; such as ASME Type 316, have 1infts that are too broad for nuclear applications. To optimize between adequate mechanical properties and minimum radiation effects, it is generally necessary to specify narrow composition ranges (especially of the minor elements) and to use special processing methods such as double vacuum melting. Some indications have been found that special thermomechanical working processes may be beneficial, e.g., a process that produces fairly large carbide precipitates crossing grain boundaries results in less deterioration in ductility during service. (15) This area has not been well explored, and caution must be exercised in proceeding without taking into account the possible effects of radiation in modifying thermally stable microstructures. 
In sumnary, the designer of nuclear plants generally works within stress and temperature ranges that appear to be capable of being met by commercially available alloys. However, the radiation environment produces unusual effects on these alloys; one is the change of microstructure by void and cluster formation together with precipitate modification, and the other is the change in diffusion rates or the "effective temperature." The former is time dependent, the latter is time independent and both affect mechanical properties. Hence, the nuclear designer must be provided with data such as creep rates and ductility limits for given stress levels as functions of neutron dose, dose rate, and spectrum as well as temperature. This makes alloy improvement and optimization a slow and expensive process. Not surprisingly, the designer of ten attempts to by-pass this process by using safety factors of large magnitude or by attempting to design around the problems. However, the economic incentives to develop new alloys are sufficiently strong to provide convincing arguments for following this lengthy and difficult process. (1) Consequently, sizeable alloy development programs in support of advanced nuclear reactors are under way in most of the major industriaftzed countries. 


\section{REFERENCES}

1. Huebotter, P.R., and T.R. Bump, "Radiation-Induced Voids in Metals," J.W. Corbett and L.C. Ianniello (eds.), USAEC Report CONF-710601, 1972, pp. 84-124.

2. Bullough, R and R.C. Perrin, ibid., p. 769.

3. Katz, J.L. and H. Wiedersich, ibid., p. 825.

4. Draley, J.E., B.R.T. Frost, D.M. Gruen, M.S. Raminsky, and V.A. Maroni, Interscience Energy Conversion Conference, Proceedings, 1971, p. 38 , published by Society of Automotive Engineers, Inc.

5. Wiedersich, H., M.S. Kaminsky, and K.M. Zwilsky, "Surface Effects in Controlled Fusion," North-Holland Publishing Co., 1974.

6. Santhanam, A.T., A. Taylor, and S.D. Harkness, Nucl. Met. 18, 302, (1973).

7. Loomis, B.A., A. Taylor, T.E. Klippert, and S.B. Gerber, Nucl. Met. 18, 332 (1973).

8. Ne1son, L.j., J.A. Hudson, and D.J. Mazey, J. Nuc1. Mater. 44, 318 (1972).

9. Downey, M.E. and B.L. Eyre, Phil. Mag. 11, 53, (1965).

10. Loomis, B.A., A. Taylor, and S,A. Gerber, IEEE Publication No. CH0843NPS, PP. 46 48, 1974 .

11. Okamoto, P.R. and H. Wiedersich, J. Nuc1. Mater. 53, 336 (1974).

12. Brailsford, A.D., J. Nucl. Mater. 56, 7 (1975).

13. Lam, N.Q. and R.A. Johnson, Paper submitted to Conference on Computex Simulation for Materials Applications, to be held April 19-21, 1976 at Gaithersburg, Maryland.

14. Bloom, E.E. and J.S. Stlegler, private communication.

15. Harries, D.R. and A.C. Roberts, ASTM Special Technical Publication No. 426, P. 21, 1967. 


\section{FIGURES}

1. Plan view of a fast-breeder reactor (EBR-II) showing the packing of hexagonal assemblies.

2. Cross section of a typlcal LMFBR fuel subassembly showing the regular close packing of many small fuel elements.

3. Approximate curves of vold swelling versus irradiation temperature in stainless steel at three fluence levels.

4. Vertical section of an LMFBR core showing the points of support for the subassemblies.

5. Schematic representation of the deflection of subassemblies due to differential swelling and compensation by creep.

6. Radiation-creep curve for Type 316 stainless steel in the core of the EBR-II reactor.

7. Transmission-electron micrograph of Irradiated stainless stee1 showing volds.

8a. Fe-Cr-N1 phase diagram at the $625^{\circ} \mathrm{C}$ isotherm showing swelling behavior as a function of composition.

8b. The same data plotted in the form of swelling versus nickel content of commerclal synthetic or pure alloys.

9. Swelling of an Fe-15Cr-20N1 alloy at $675^{\circ} \mathrm{C}$ and 140 dpa as a function of various minor alloy additions.

10. Schematic representation of a Tokamak fusion device.

11. Cross section of a fusion reactor.

12. Possible radiation processes that occur in the first wall of a fusion reactor.

13. Neutron effects in fusion- and fission-reactor materials.

14. Ductility as a function of temperature in vanadium containing 0 and $25 \mathrm{ppm}$ of injected hellum.

15. The change in $\mathrm{Ni}_{3} \mathrm{Al}$ precipitate size and density in a nicke1aluminum alloy as a function of charged-particle irradiation dose at $550^{\circ} \mathrm{C}$.

16. Vold size and number density in niobium containing various levels of oxygen after nickel ion bombardment. 
FIGURES (Contd.)

17a. Transmission-electron micrographs of electron-irradiated $18 / 8 / \mathrm{Si}$ stainless steel. Silicon has segregated to the void surfaces-note the circled regions.

17b. Auger spectroscopy of surfaces in $18 / 8 / \mathrm{Si}$ stainless steel showing silicon segregation after irradiation. 


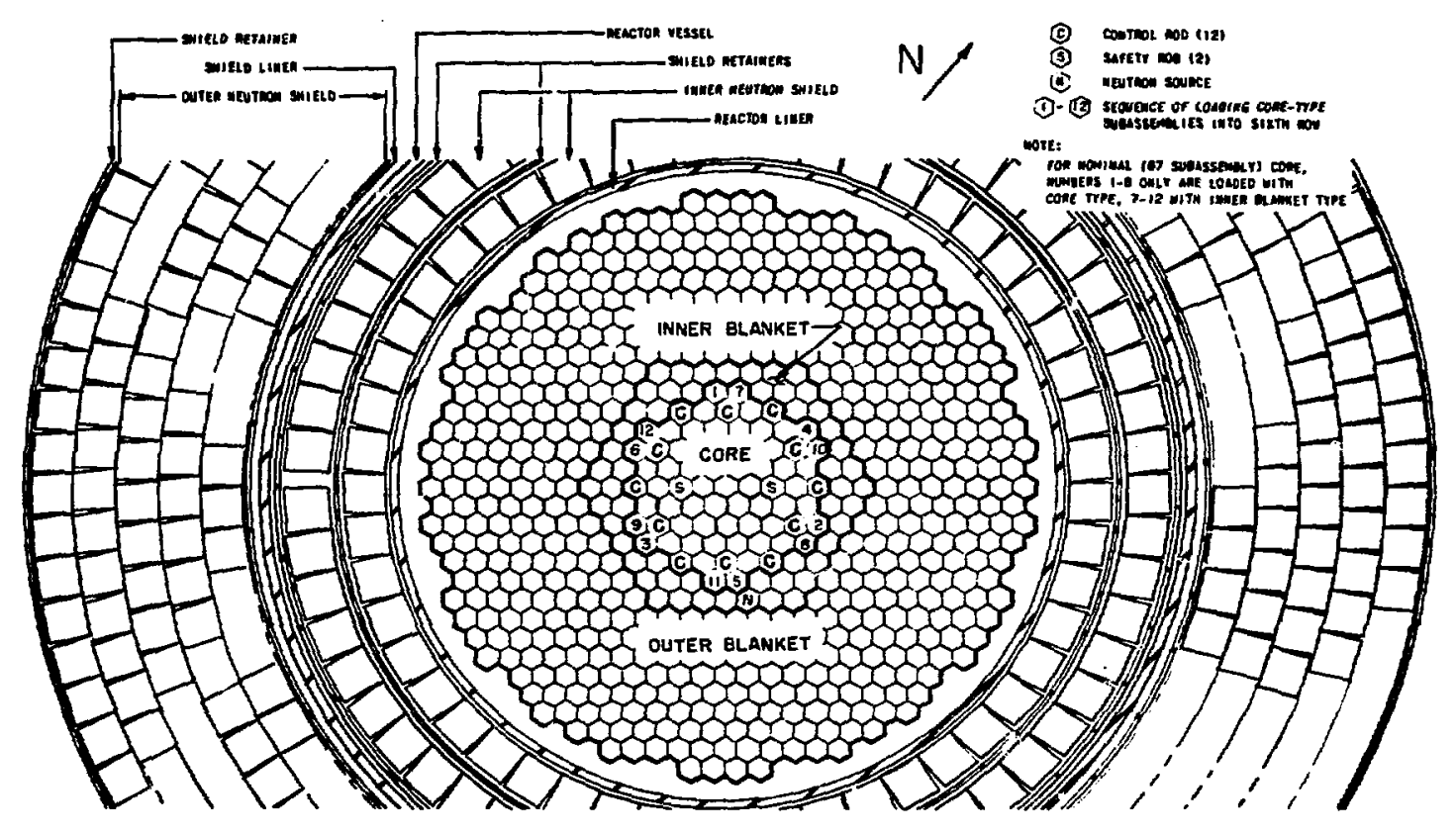

Fig. 1. Plan vlew of a fast-breeder reactor (EBR-II) showing the packing of hexagonal assemblies. 


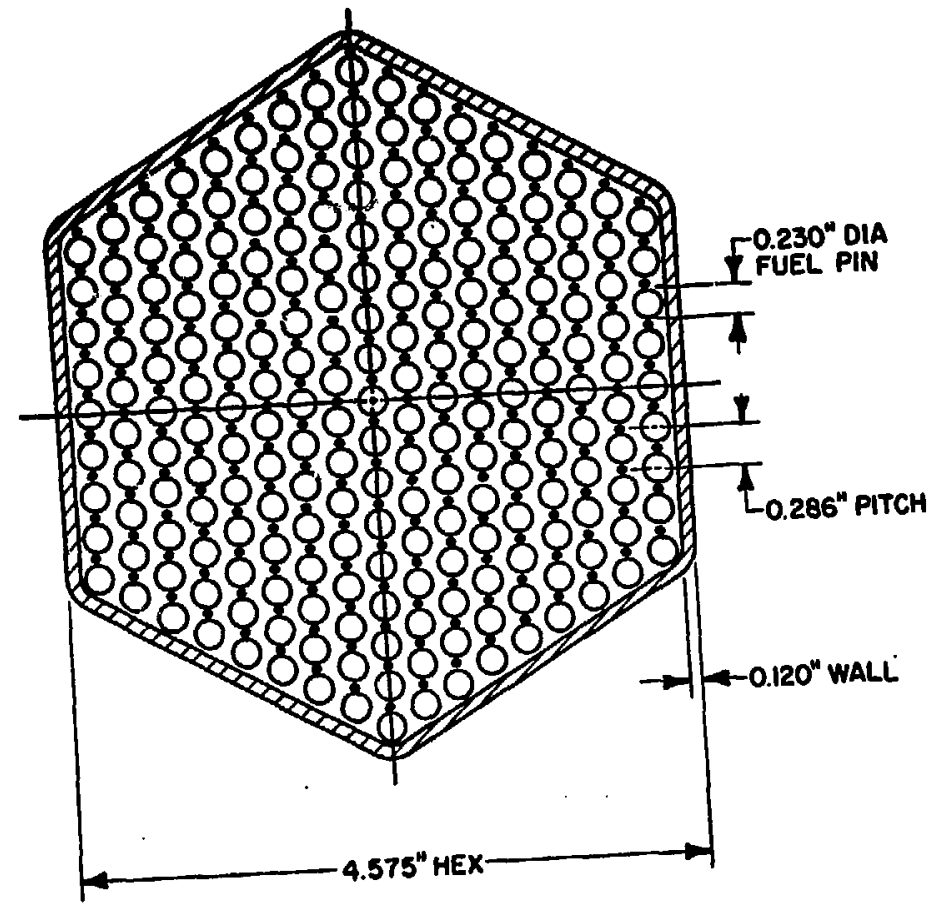

Fig. 2. Cross section of a typical LMFBR fuel subassembly showing the regular close packing of many small fuel elements.

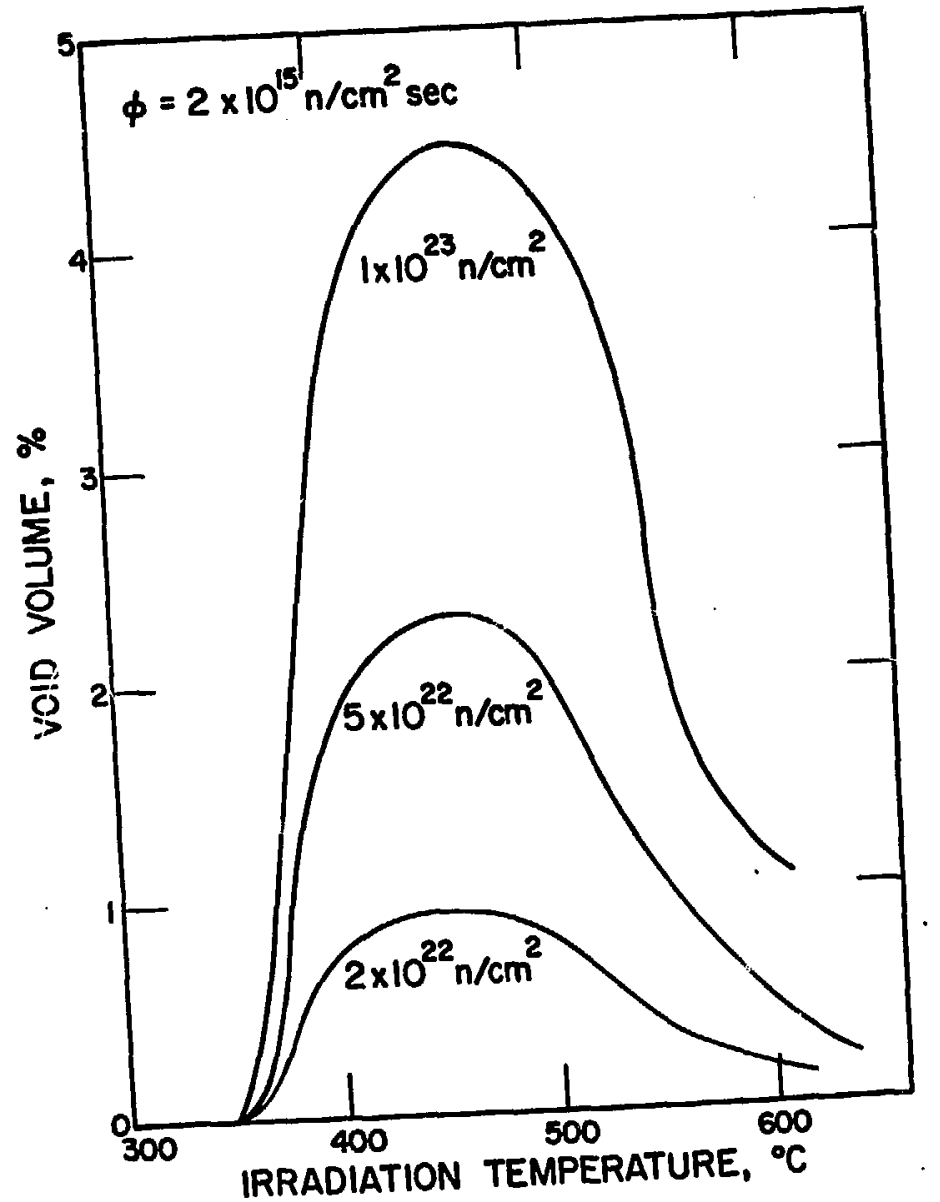

Fig. 3. Approximate curves of void swelling versus ir列 fluence levels. 


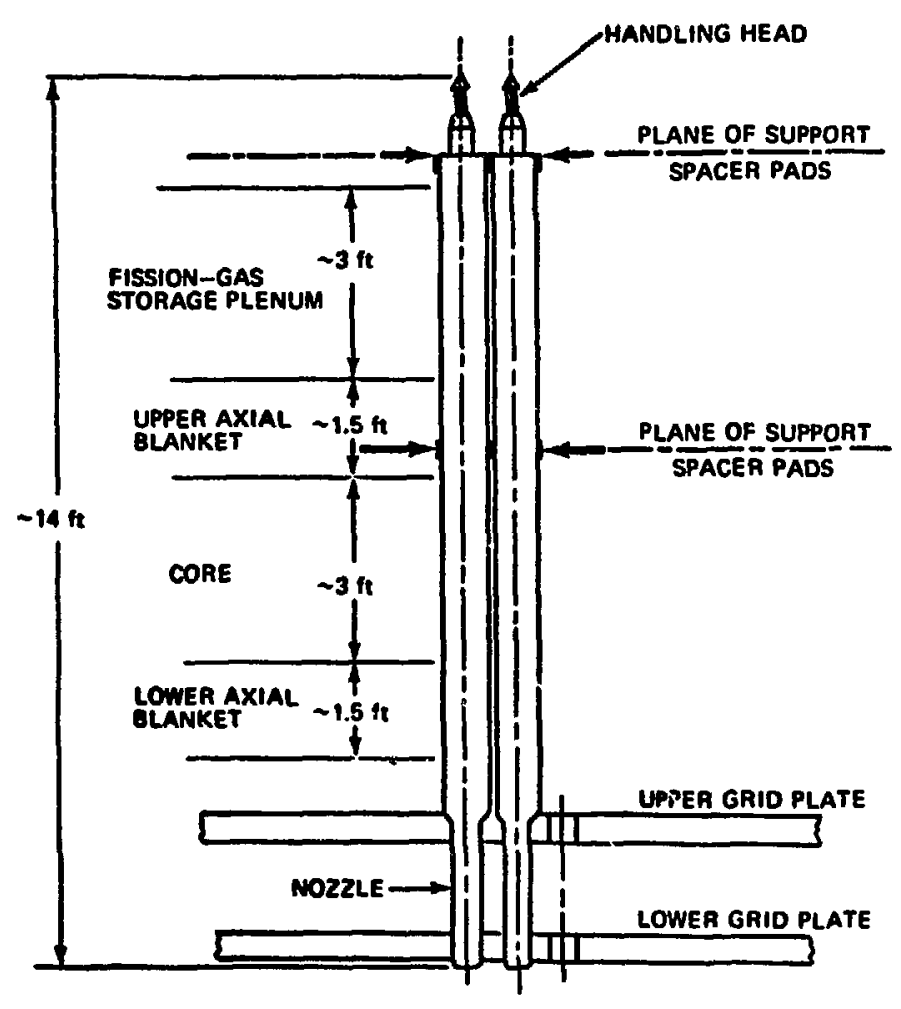

Typkel LMFak core-support concept.

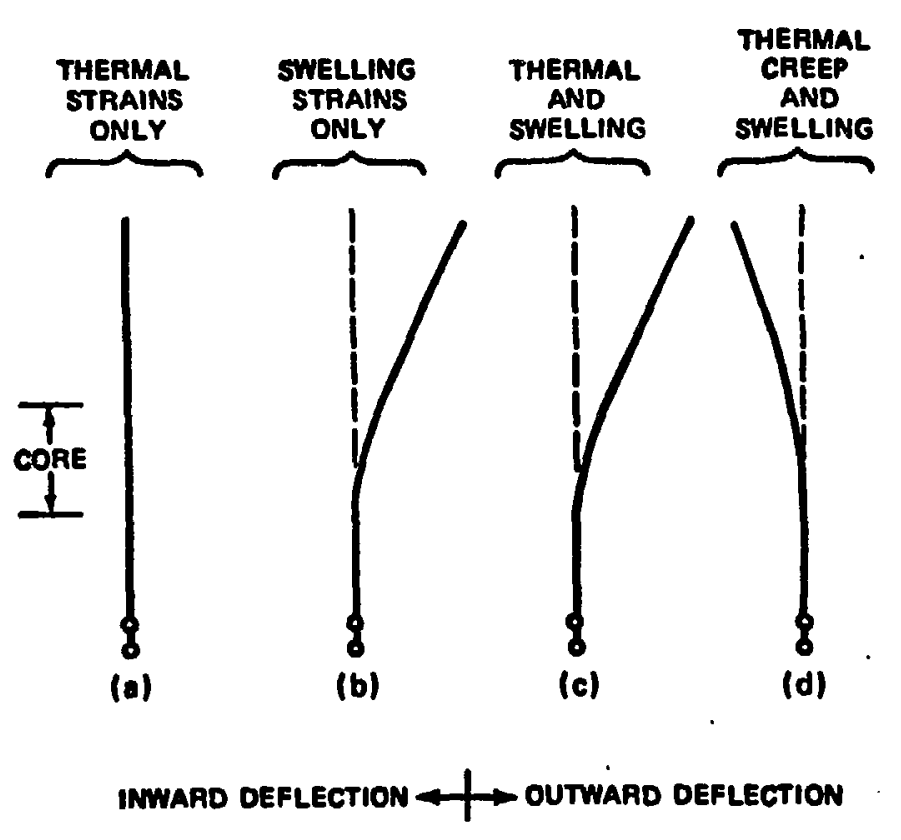

F1g. 5. Schematic representation of the deflection of subassemblies due to differential swelling and compensation by creep.

Fig. 4. Vertical section of an LFBR core showing the pointe of support for the subassemblies. 


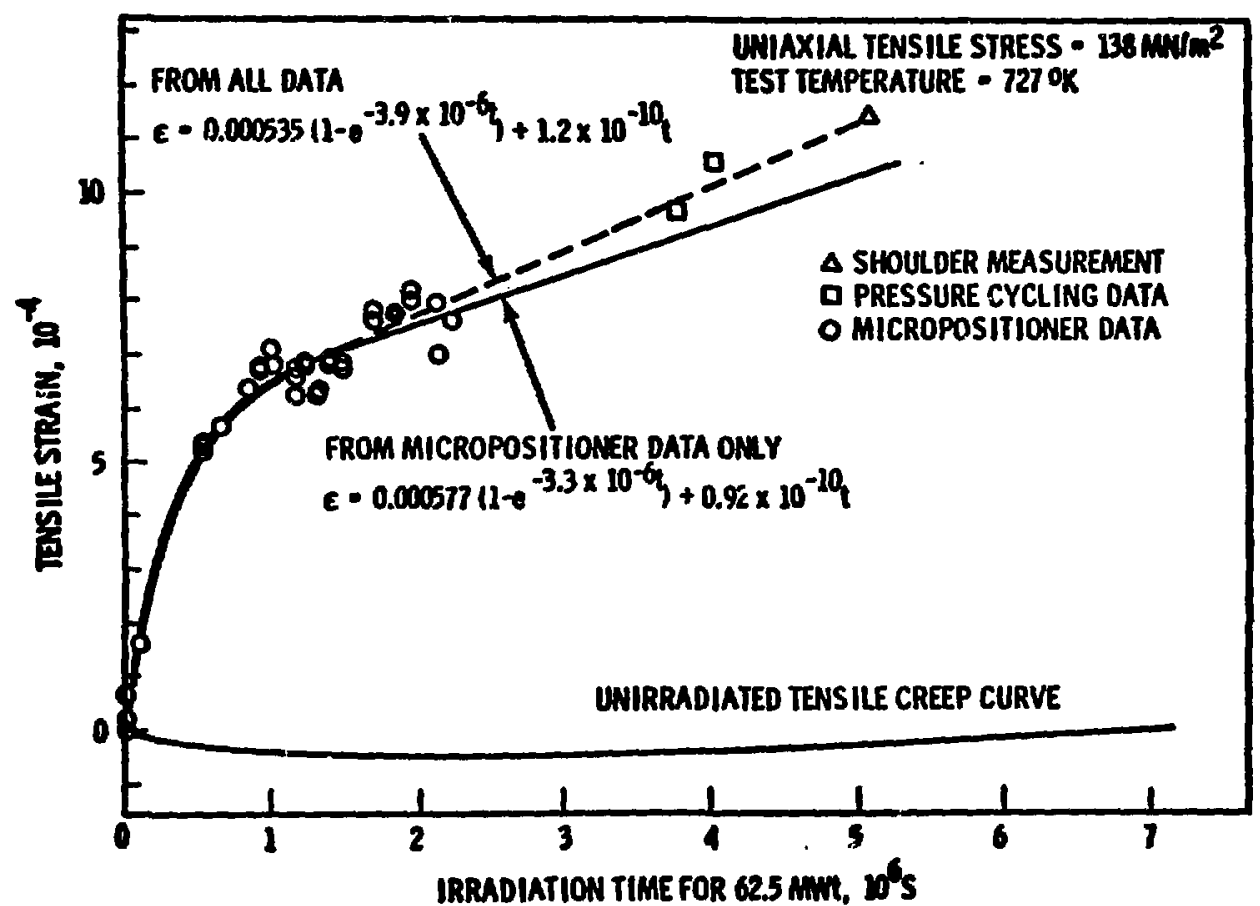

F18. 6. Radiation-creep curve for Type 316 stainless steel in the core of the BBR-II reactor.

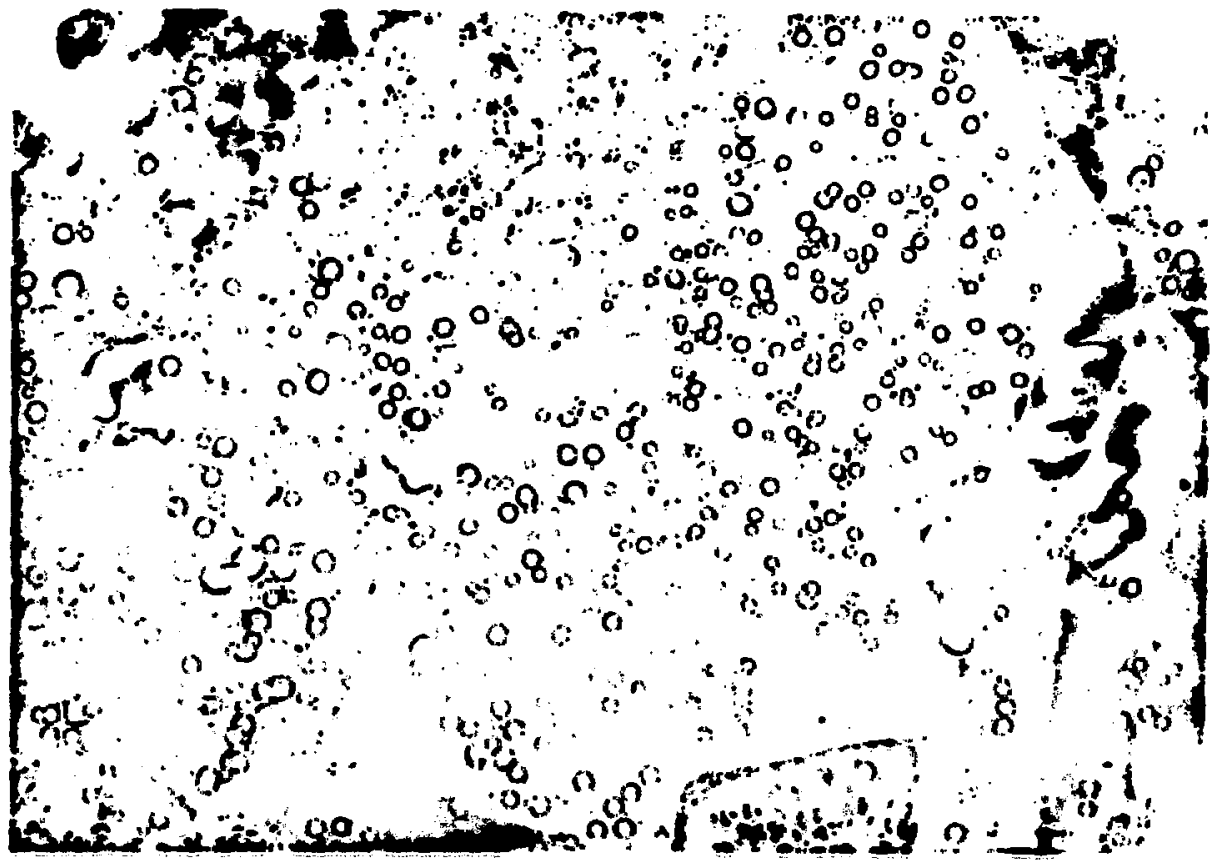

F18. 7. Trangutesion-electron alcrograph of Irradited stainless steel showing volde. 


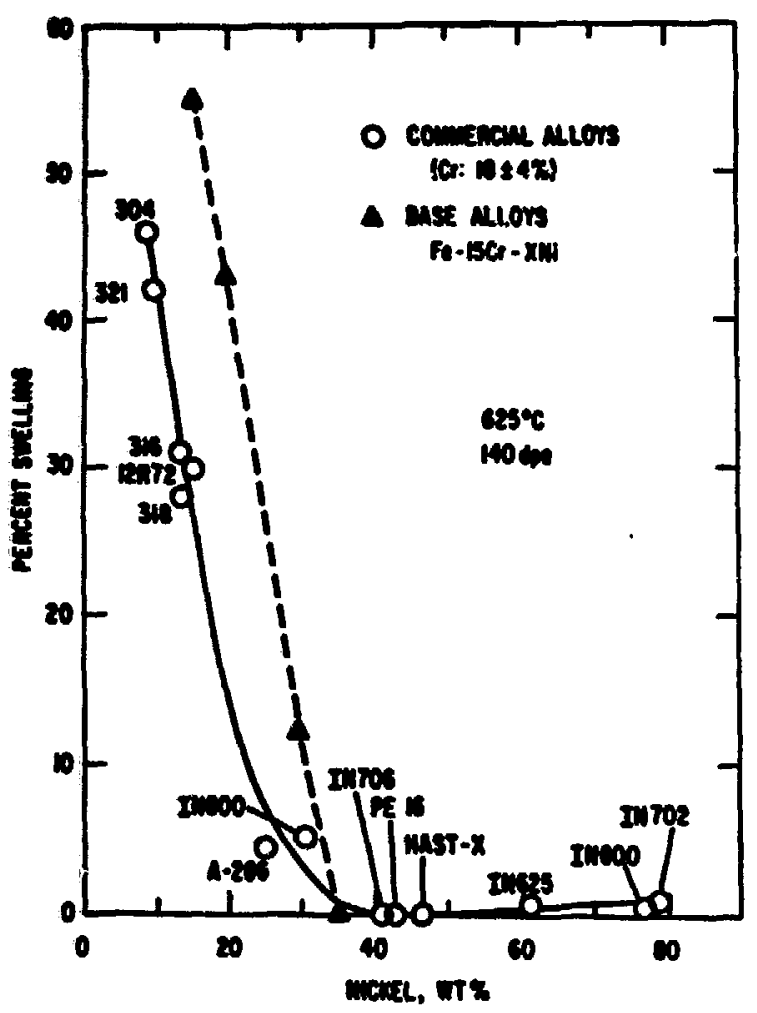

F1g. 8a. Fe-Cr-Mi phase diagran at the $625^{\circ} \mathrm{C}$ 1sotherm showing swelling behavior as a function of composition.

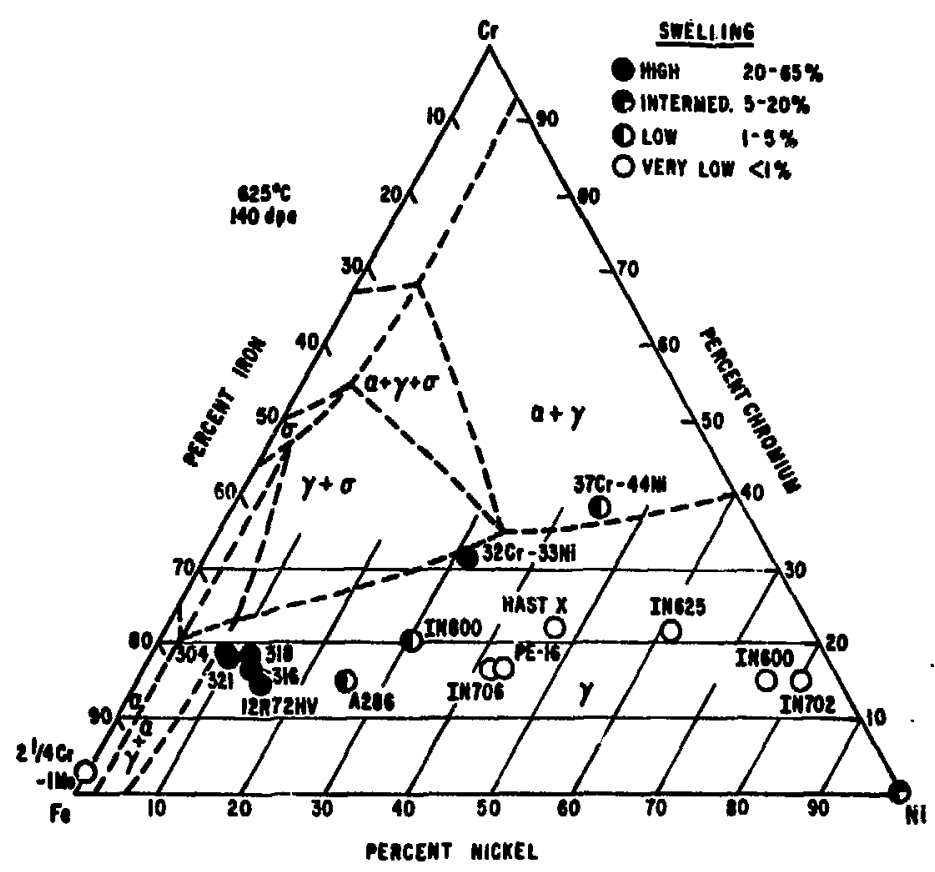

F1g. 8b. The same data plotted in the form of awelling versus nickel content of commercial synthetic or pure alloys. 


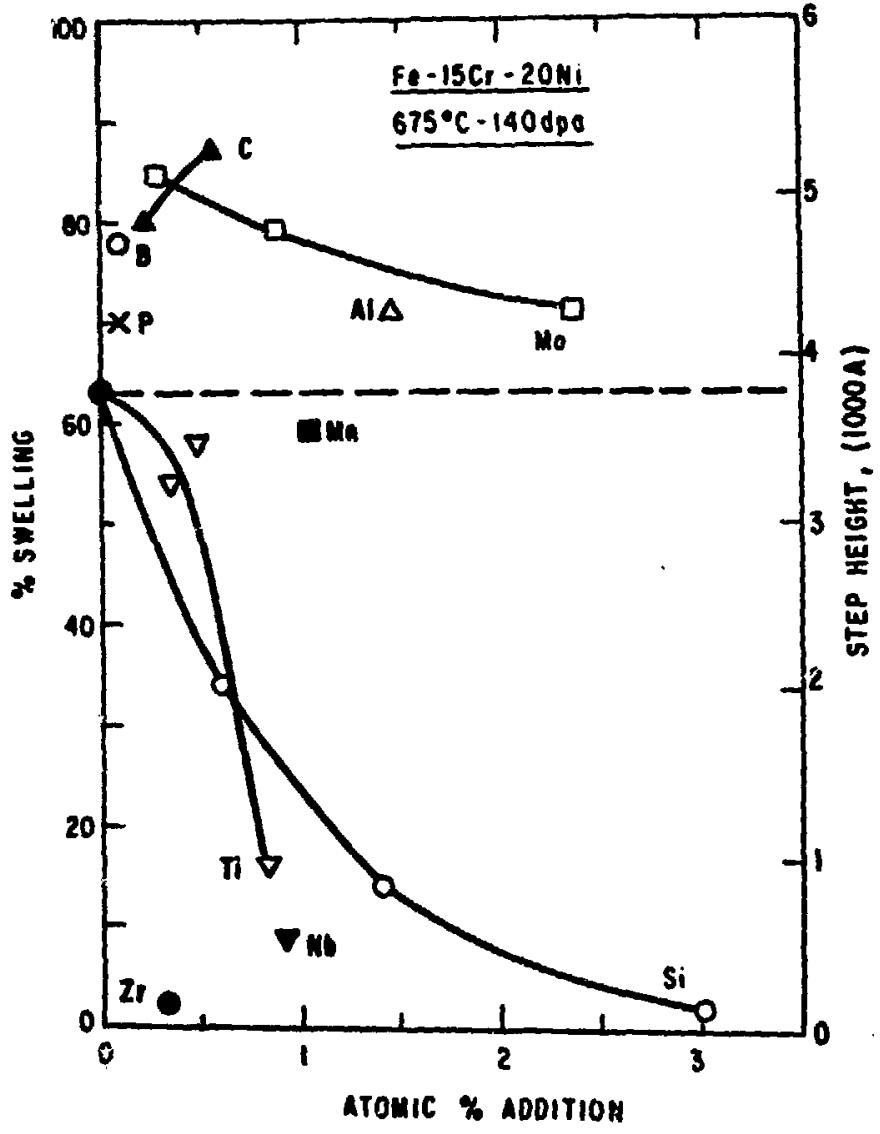

F18. 9. Swelling of an Fe-15Cr-20N1 alloy at $675^{\circ} \mathrm{C}$ and 140 dpa as a function of various minor alloy additions.

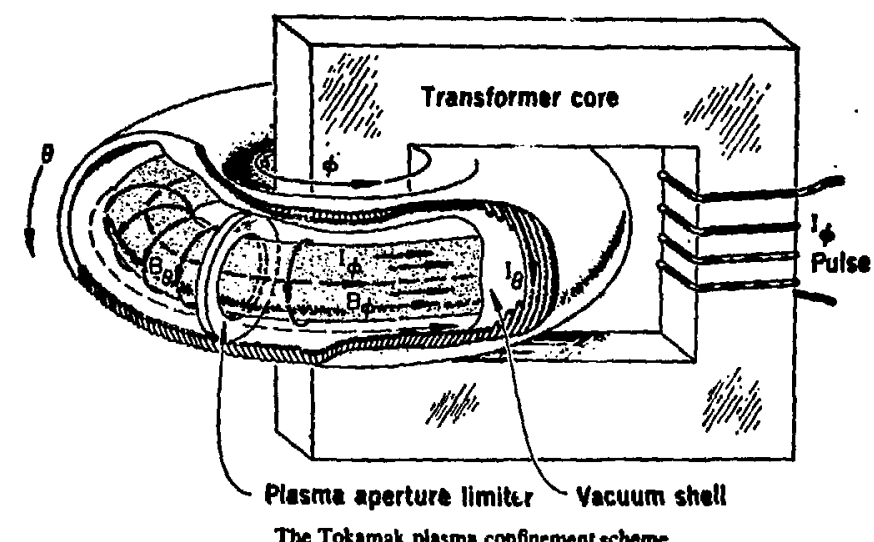

Fig. 10. Schematic representation of a Tokamak fusion device. 


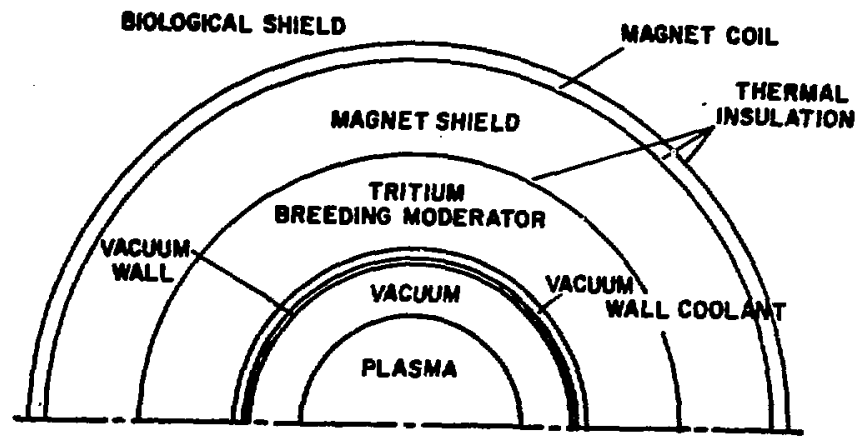

Fig. 11. Cross section of a fusion reactor.

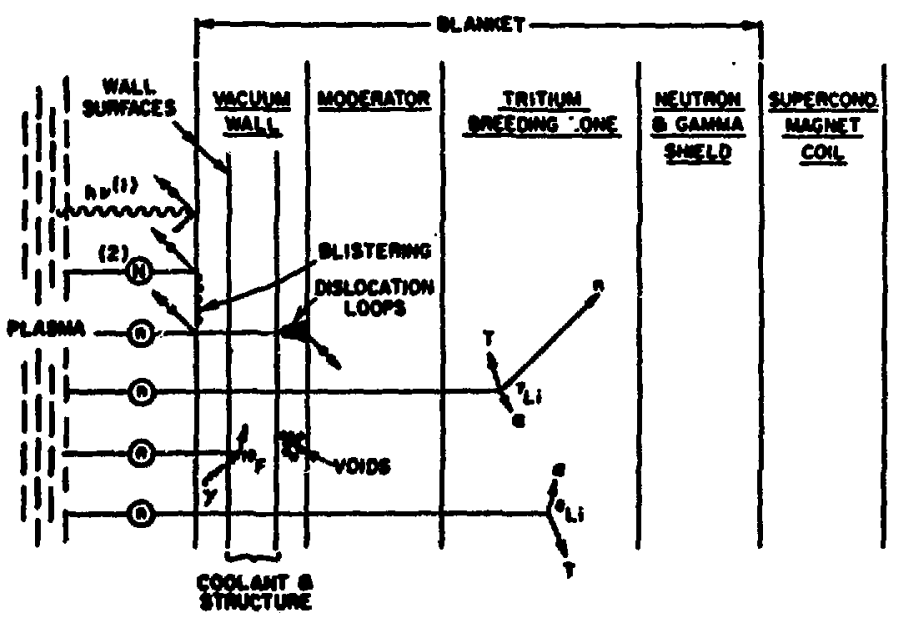

(1) $Y$ bi, $x$ -

(e) newmal atom on morecuse

818. 12. Posstble radiation processes that occur in the first wall of a fuston reactor. 


\section{NEUTRON-RADIATION DAMAGE}

\begin{tabular}{|c|c|c|}
\hline & $\begin{array}{l}\text { FUSION REACTOR } \\
\text { NIODIUM WALL } \\
\end{array}$ & $\begin{array}{l}\text { EBR II FISSION } \\
\text { REACTOR STAINLESS } \\
\text { STEEL CLADDING } \\
\end{array}$ \\
\hline NEUTRON FLUX & $4 \times 10^{15} \mathrm{n} / \mathrm{cm}^{2} \mathrm{sec}$ & $4 \times 10^{15} \mathrm{n} / \mathrm{cm}^{2} \mathrm{sec}$ \\
\hline MEUTRON ENERGY & 14.1 mev & 1 mer \\
\hline DISPLACEMENT RATE & 200 atoms/rear & 100 atoms/year \\
\hline HYDROGEN PRODUCIION & $900 \mathrm{ppm} /$ rear & 30 pp/yeor \\
\hline HELIUM PRODUCTHON & $300 \mathrm{ppm} / \mathrm{yeor}$ & $20 \mathrm{ppm} /$ year \\
\hline ZIRCONIUM PRODUCTION & $10^{4} \mathrm{ppm} /$ year & - \\
\hline VOLUME SWELLING & (1\%/rearpt) & $3 \%$ \\
\hline OPERATING TEMPERATURE & $600^{\circ}-1000^{\circ} \mathrm{C}$ & $470^{\circ} \mathrm{C}$ \\
\hline
\end{tabular}

F18. 13. Neutron effects in fusion- and fission-reactor materlals.

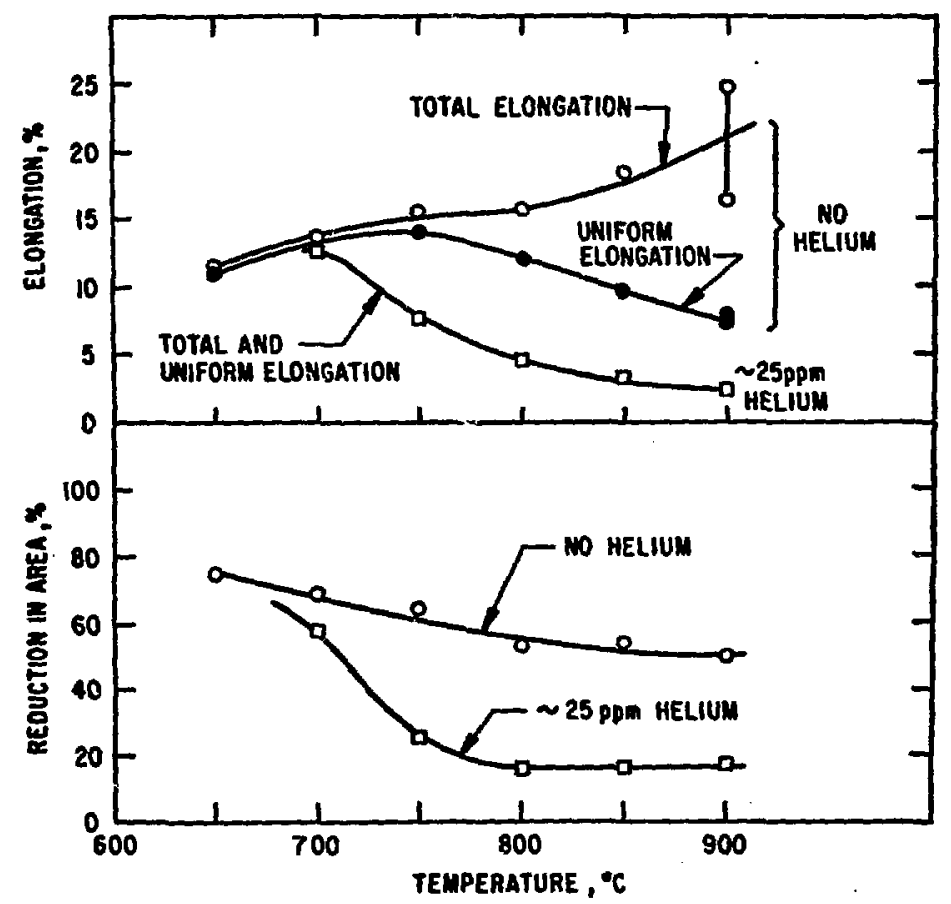

Fig. 14. Ductility as a function of temperature in vanadium containing 0 and $25 \mathrm{ptpm}$ of infected hellum. 


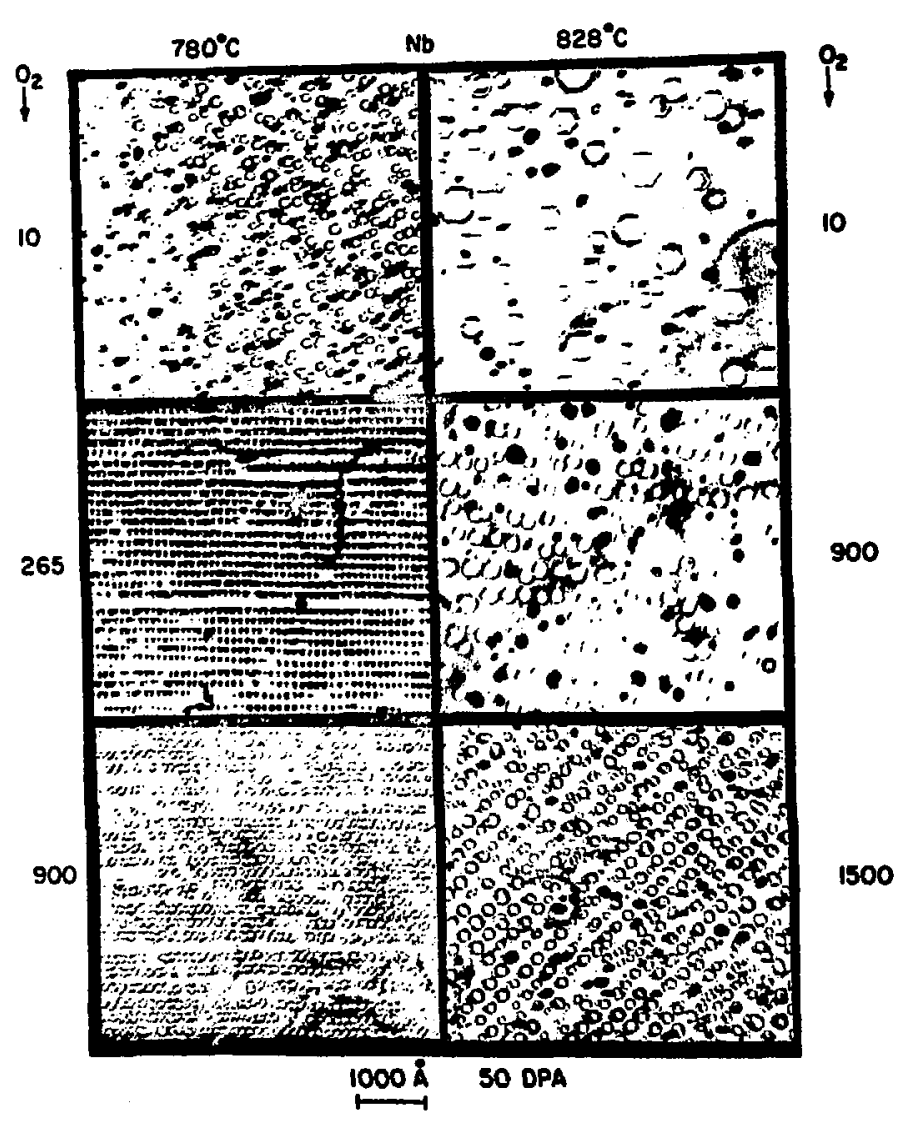

Fig. 15. The change in $\mathrm{Ni}_{3} \mathrm{AI}$ precipitate size and density in a nickel-aluminum alloy as a function of charged-particle irradiation dose at $550^{\circ} \mathrm{C}$.
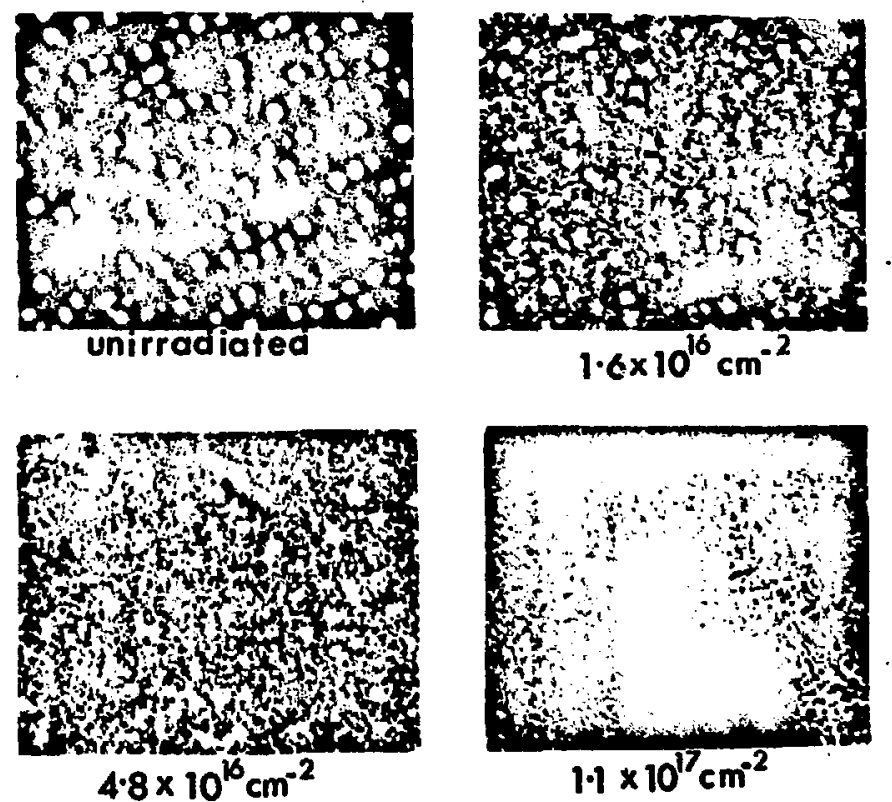

$1 \cdot 1 \times 10^{17} \mathrm{~cm}^{-2}$

$0.1 \mu$

Fig. 16. Vold gize and number density in nioblum containing various levels of oxygen after nickel ton bombardment. 
$1 \mathrm{Nev}$ Electron Irradiated $18 / 8 / 5$ i Austenitic Steel Temperature $=500 \mathrm{C}$.

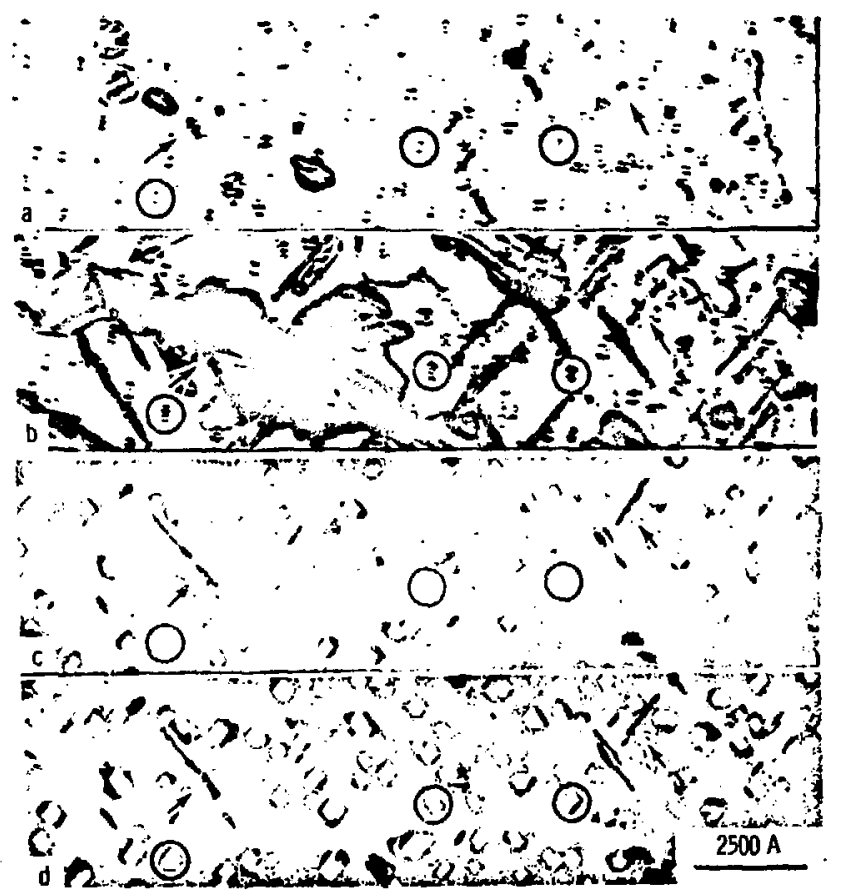

Fig. 17a. Transmission-electron micrographs of electronirradiated $18 / 8 / \mathrm{Si}$ stainless steel. Silicon has segregated to the vold surfaces--note the circled regions.

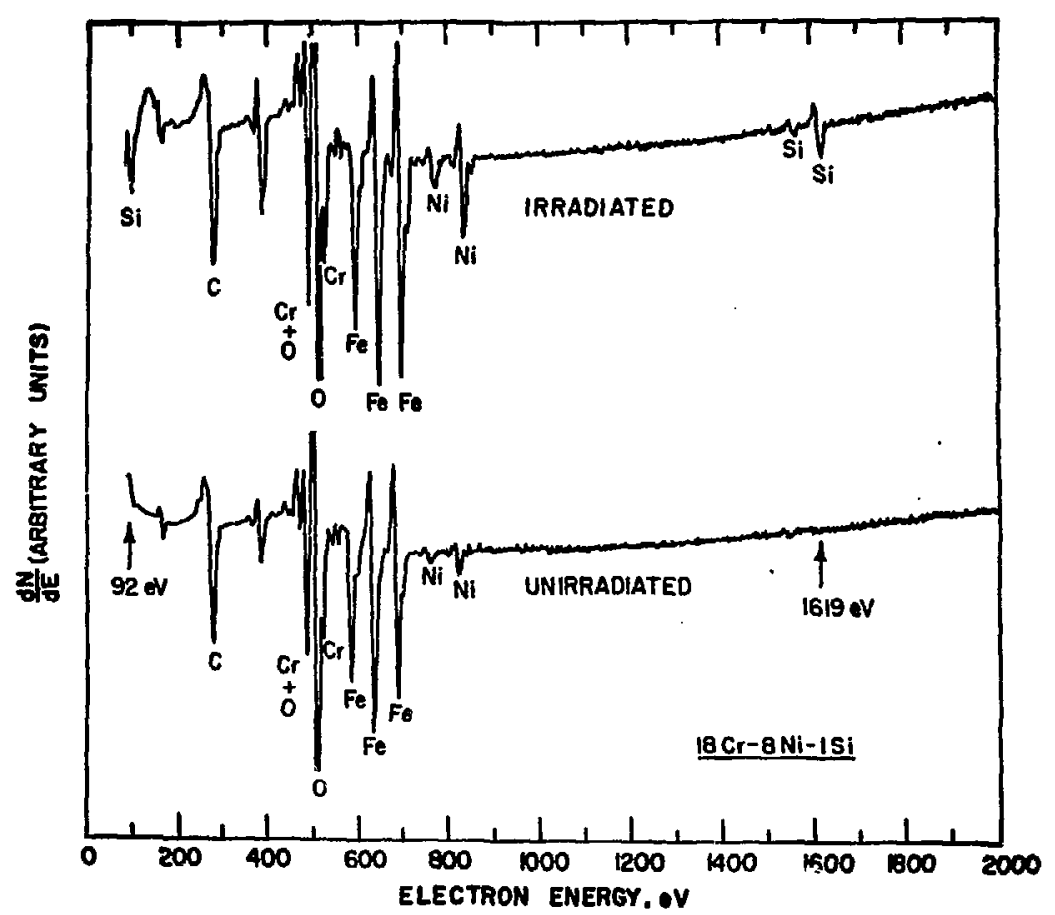

Fig. 17b. Auger spectroscopy of surfaces in 18/8/S1 stainless steel showing silicon segregation after irradiatior. 